\title{
Plumbonacrite Identified by X-ray Powder Diffraction Tomography as a Missing Link during Degradation of Red Lead in a Van Gogh Painting ${ }^{\star *}$
}

\author{
Frederik Vanmeert, Geert Van der Snickt, and Koen Janssens*
}

\begin{abstract}
Red lead, a semiconductor pigment used by artists since Antiquity, is known to undergo several discoloration phenomena. These transformations are either described as darkening of the pigment caused by the formation of either plattnerite $\left(\beta-\mathrm{PbO}_{2}\right)$ or galena $(\mathrm{PbS})$ or as whitening by which red lead is converted into anglesite or (hydro)cerussite. X-ray powder diffraction tomography, a powerful analytical method that allows visualization of the internal distribution of different crystalline compounds in complex samples, was used to investigate a microscopic paint sample from a Van Gogh painting. A very rare lead mineral, plumbonacrite $\left(3 \mathrm{PbCO}_{3} \cdot \mathrm{Pb}(\mathrm{OH})_{2} \cdot \mathrm{PbO}\right)$, was revealed to be present. This is the first reported occurrence of this compound in a painting dating from before the mid $20^{\text {th }}$ century. It forms the missing link between on the one hand the photoinduced reduction of red lead and on the other hand (hydro)cerussite, and thus sheds new light on the whitening of red lead.
\end{abstract}

X-ray powder diffraction (XRPD) mapping can be used to identify, visualize and to a certain extent quantify the different crystalline components that are present in complex heterogeneous paint systems. ${ }^{[1]}$ At state-of-the-art synchrotron radiation facilities this can be done on the (sub)micrometer scale. In the past 10 years, combined microscopic X-ray fluorescence and X-ray powder diffraction ( $\mu \mathrm{XRF} / \mu \mathrm{XRPD})$ mapping experiments performed on samples extracted from works of art have been used for e.g. the identification of various pigments and artist materials, ${ }^{[2]}$ as well as their degradation products, ${ }^{[3]}$ and even the imaging of a complete painting. ${ }^{[4]}$ However, an intrinsic limitation of two-dimensional (2D) mapping remains the loss of depth information as projection images are obtained. Therefore, in order to investigate the stratigraphy of a paint system, typically a cross-section of a paint sample needs to be prepared, consuming to a lesser or greater extent part of the (often unique or very rare) sample. With $\mu$ XRPD tomography the inner distribution of the crystalline components present in such samples can be visualized without physically cross-sectioning the material under investigation. ${ }^{[5]}$ Although the

$\left[{ }^{\star}\right] \quad$ F. Vanmeert, Dr. G. Van der Snickt, Prof. Dr. K. Janssens Antwerp X-ray Analysis, Electrochemistry \& Speciation University of Antwerp

Groenenborgerlaan 171, 2020 Antwerp (Belgium)

E-mail: koen.janssens@uantwerpen.be

https://www.uantwerpen.be/en/rg/axes/

$\left[{ }^{* \star}\right] \quad$ The authors acknowledge L. Van der Loeff and M. Leeuwestein (Kröller-Müller Museum) for providing the paint sample. We thank Dr. J. Jaroszewicz (WUT) for performing the CT measurements. This research was carried out at the light source PETRA III at DESY, a member of the Helmholtz Association (HGF). We would like to thank Dr. G. Falkenberg and the members of his team for their assistance in using beam line P06. capabilities of this technique have been demonstrated on various complex materials, ${ }^{[6]}$ it has been scarcely used on cultural heritage samples. ${ }^{[7]}$

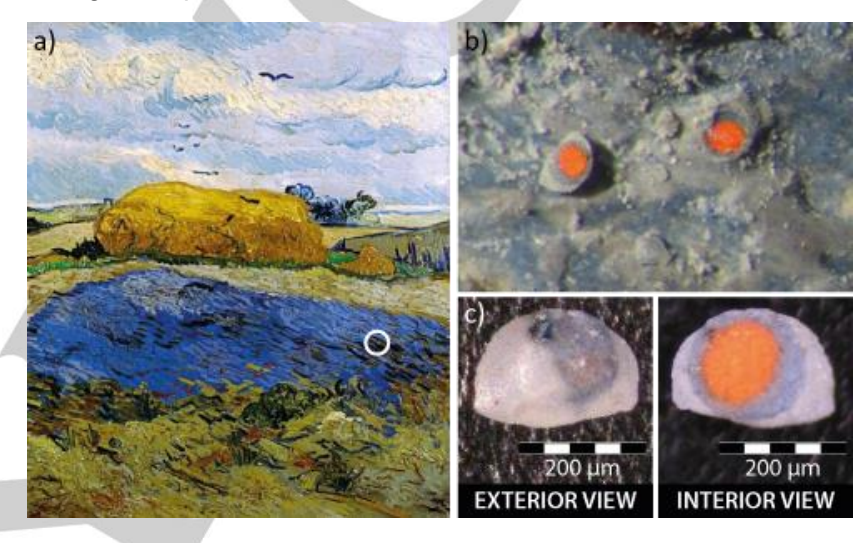

Figure 1. a) Photograph of Wheat stack under a cloudy sky by Van Gogh (October 1889, oil on canvas, Kröller-Müller Museum, NL). The sample area is indicated by the white circle; b) Detail of the severed pustular mass on the painting surface; c) Detail of the paint sample.

In this work we performed combined $\mu \mathrm{XRF} / \mu \mathrm{XRPD}$ imaging of a minute sample obtained from the painting Wheat stack under a cloudy sky by Vincent van Gogh (October 1889, oil on canvas, Kröller-Müller Museum, NL). The sample consists of a severed pustular mass revealing a bright orange-red core (about $100 \mu \mathrm{m}$ in diameter) surrounded by a light blue tinted layer and a gray outer layer that partially covers the pustular mass (Figure 1). This outer layer consists of finely grained particles, rich in both $\mathrm{Zn}$ and $\mathrm{Pb}$ (Figure 2a), that were applied onto the original blue paint layer which is made up of coarse grains (Figure 2c). The compoundspecific distribution maps (Figure $2 \mathrm{~b}$ ) show that this gray layer contains a mixture of the pigments zinc white (zincite, $\mathrm{ZnO}$ ) and lead white (hydrocerussite, $2 \mathrm{PbCO}_{3} \cdot \mathrm{Pb}(\mathrm{OH})_{2}$ ). Although both white pigments were part of Van Gogh's palette,${ }^{[8]}$ this outer layer was not originally present but was added later, probably during retouching. While the lead white used in this outer layer consists only of basic lead carbonate, a different lead white composition is found in the light blue layer underneath that contains both neutral (cerussite, $\mathrm{PbCO}_{3}$ ) and basic lead carbonate (hydrocerussite). The blue color of this layer could originate from cobalt blue, a pigment frequently used by Van Gogh, as a significant Co XRF signal is observed. In the bright red core of the pustule, a third lead-containing pigment identified as red lead is present. 
a) $\mu X R F$ mapping

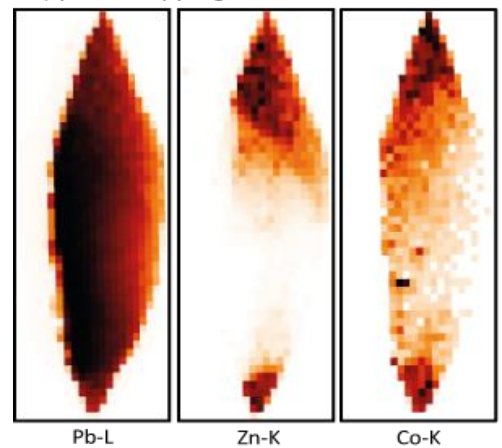

b) $\mu$ XRPD mapping

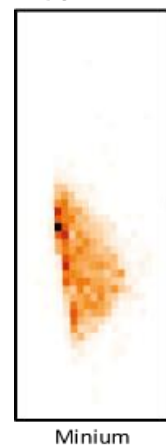

$\left(\mathrm{Pb}_{3} \mathrm{O}_{4}\right)$

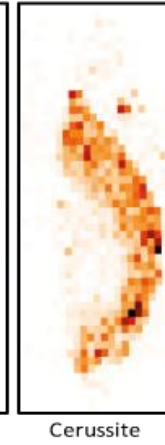

$\left(\mathrm{PbCO}_{3}\right)$

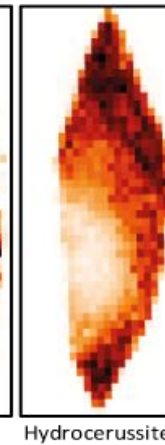

Hydrocerussite
$\left(2 \mathrm{PbCO}_{3} \cdot \mathrm{Pb}(\mathrm{OH})_{2}\right)$ c) XRR

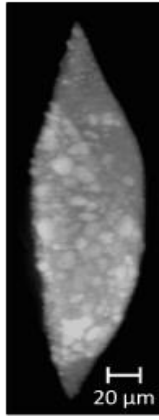

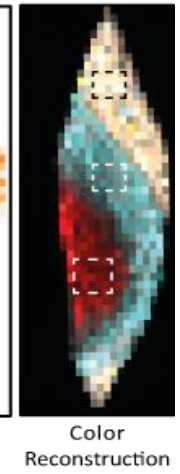

Figure 2. a) Elemental and b) phase-specific 2D distribution images of the severed pustule. Map size: $80 \times 255 \mu \mathrm{m}^{2}$; Pixel size: $4 \times 5 \mu \mathrm{m}^{2}$. Legend of the color reconstruction: minium (red), cerussite (blue), hydrocerussite (white) and zincite (orange). The dashed boxes show the regions from which averaged diffractograms were extracted (see Figures S1-3, Supporting Information); c) Xray radiography (XRR) image obtained from an X-ray absorption tomography dataset (experimental parameters see SI).

Red lead, most commonly designated with the term minium, is a semiconductor pigment used since ancient times and is thought to be one of the first artificially prepared pigments. ${ }^{[9]}$ Minium corresponds to the lead(II,IV) oxide mineral of composition $\mathrm{Pb}_{3} \mathrm{O}_{4}$ and can often be found on artworks in association with lead monoxide, either litharge (tetragonal $\mathrm{PbO}$ ) or massicot (orthorhombic $\mathrm{PbO}$ ). ${ }^{[10]}$ However, the diffraction data did not show any lead(II) oxides in the sample. The red lead pigment is known to be unstable with time. On the one hand, it is thought to play a role in the formation of lead soap protrusions where lead carbonate and lead soaps are formed through the reaction of red lead with the fatty acids present in the oil medium. ${ }^{[11]}$ On the other hand, orange, flake-like particles found in and around lead soap protrusions have been identified as minium, ${ }^{[12]}$ and are believed to have formed via remineralization usually together with lead carbonate. ${ }^{[13]}$ However, from the large grains shown to be present in the interior of the sample and the large amount of red lead present, it is most plausible that minium is the original material and not a degradation product as a result of protrusion formation. It is also known both from his letters and from the study of paint samples that Van Gogh used minium as a red pigment in his paintings from the Auvers-sur-Oise period. ${ }^{[8]}$

Next to being involved in protrusion formation, red lead can undergo severe discoloration. ${ }^{[14]}$ The most frequently

encountered color change is described as blackening of the pigment, caused by the formation of either galena $(\mathrm{PbS})$ or plattnerite $\left(\beta-\mathrm{PbO}_{2}\right)$. A second, less documented discoloration, visible as whitening or bleaching of the pigment has also been described. ${ }^{[15]}$ In this case the alteration products are shown to be either lead carbonate (neutral and/or basic) or lead sulfate $\left(\mathrm{PbSO}_{4}\right)$. Both lead carbonates described to the whitening of the pigment are present in the blue covering layer, making it difficult to conclude that whitening of the red lead is taking place. However, the $\mu$ XRPD tomograms reveal a "vacant space" between the minium core and the blue-tinted lead white layer (Figure 3). In fact a fourth lead-containing compound, plumbonacrite $\left(3 \mathrm{PbCO}_{3} \cdot \mathrm{Pb}(\mathrm{OH})_{2} \cdot \mathrm{PbO}\right)$, is found to be present in the sample (see Figure S4 in the Supporting Information), which is largely situated in this "void". To some extent an overlap between the lead white layer and plumbonacrite is visible (see also Figure S5, Supporting

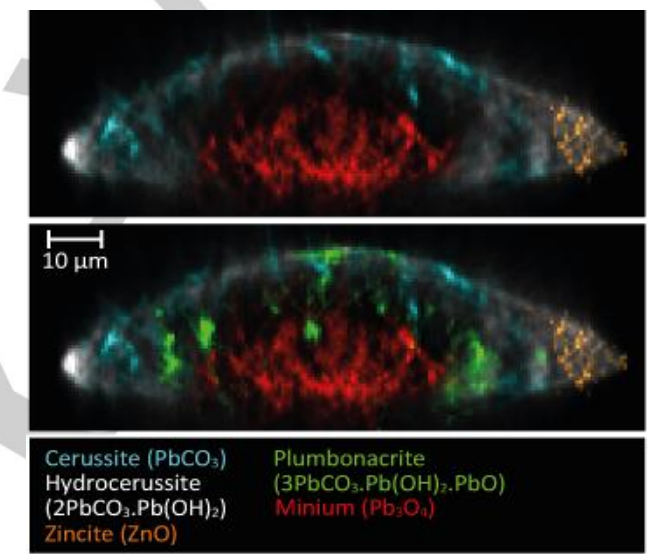

Information).

Figure 3. Color reconstructions of the inner crystalline distribution of the paint sample. Reconstructed map size: $111 \times 43 \mu \mathrm{m}^{2}$; Pixel size: $1 \times 1 \mu \mathrm{m}^{2}$. The individual phase-specific distribution images can be found in the Supporting Information (Figure S5).

Plumbonacrite, a very rare lead carbonate mineral, can be formed in aqueous systems at ambient temperature and pressure and is metastable with respect to litharge $(\mathrm{PbO})$ and hydrocerussite. ${ }^{[16]}$ The compound has been commonly reported as a corrosion product, for example in artificial ageing studies of lead samples subjected to acidic environments, ${ }^{[17]}$ and on bronzes, ${ }^{[18]}$ as well as on naturally aged objects. ${ }^{[19]}$ However, literature regarding the presence of plumbonacrite in paintings or painters materials is very scarce. Plumbonacrite, together with (hydro)cerussite, was identified as degradation product formed from lead(II) oxides upon artificial ageing. ${ }^{[20]}$ It is worth mentioning that plumbonacrite was made synthetically from the mid $20^{\text {th }} \mathrm{C}^{\left[{ }^{21]}\right.}$ Before this date, to the best of our best knowledge, this phase was never detected on paintings, either as part of lead white mixtures or as a pure compound.

In our case, the presence of this carbonate-poor lead compound in between the red lead and the carbonate-rich lead white layer strongly suggests that plumbonacrite is present as an intermediate degradation product formed during the whitening of minium. Since $\mathrm{PbO}$, a remnant of the red lead production 
process ${ }^{[14]}$ is more reactive than $\mathrm{Pb}_{3} \mathrm{O}_{4}$, it may have initiated the degradation process. Alternatively, minium itself can be photoactivated, leading to the reduction of $\mathrm{Pb}^{\mathrm{IV}}$ to $\mathrm{Pb}^{\mathrm{I}}$. For the latter pathway, we propose an additional step in the photochemical reaction described by Zhou, et al. ${ }^{[22]}$ (Scheme 1).

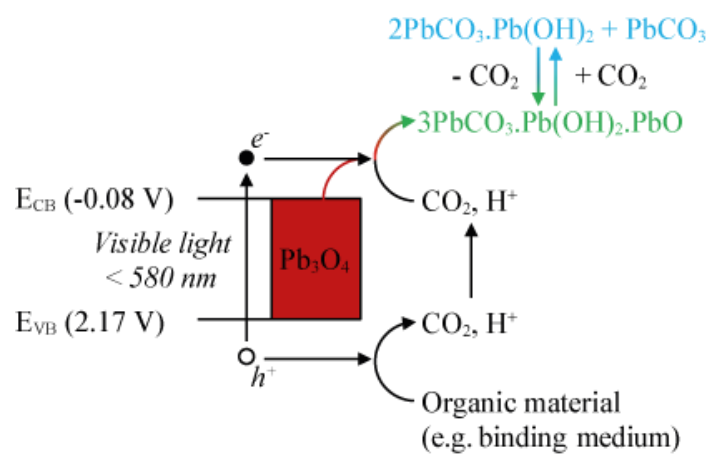

Scheme 1. Proposed pathway for the photochemical degradation of $\mathrm{Pb}_{3} \mathrm{O}_{4}$ under visible light irradiation. Conduction and valence band potentials, respectively $\mathrm{E}_{\mathrm{CB}}$ and $\mathrm{E}_{\mathrm{V}}$, are given relative to the normal hydrogen electrode $(\mathrm{NHE}){ }^{[22]}$

Electron hole pairs are formed between the valence $(2.17 \mathrm{~V})$ and conduction band $(-0.08 \mathrm{~V})$ of minium upon exposure to visible light $(\lambda<580 \mathrm{~nm})$. The electrons generated in the conduction band can reduce $\mathrm{Pb}^{\mathrm{IV}}$ present in minium to $\mathrm{Pb}^{\| 1}$ which in turn reacts with $\mathrm{CO}_{2}$ to form one or more lead carbonate compounds. ${ }^{[22]}$ The required $\mathrm{CO}_{2}$ can be formed in situ through the oxidative decarboxylation of free fatty acids present in e.g. the binding medium. ${ }^{[11]}$ However the influence of atmospheric $\mathrm{CO}_{2}$ has also been proven to affect the whitening of red lead. ${ }^{[15]}$ Here we propose an intermediate step in the fixation of $\mathrm{CO}_{2}$ where a gradual uptake of $\mathrm{CO}_{2}$ leads to the formation of plumbonacrite. Depending on the availability of $\mathrm{CO}_{2}$, the initially formed plumbonacrite layer can take up more $\mathrm{CO}_{2}$ to form hydrocerussite and finally cerussite. Indeed, such a gradual uptake of $\mathrm{CO}_{2}$ by lead(II) oxide has been shown to exist. ${ }^{[16 \mathrm{~b}]}$

$\mathrm{PbO} \rightleftharpoons 3 \mathrm{PbCO}_{3} \cdot \mathrm{Pb}(\mathrm{OH})_{2} \cdot \mathrm{PbO} \rightleftharpoons 2 \mathrm{PbCO}_{3} \cdot \mathrm{Pb}(\mathrm{OH})_{2} \rightleftharpoons \mathrm{PbCO}_{3}$

Different stages of equilibrium (1) can be observed at different locations in Figure S5 (Supporting Information). Thus, our observations are fully consistent with the results obtained by Taylor and Lopata, ${ }^{[16 b]}$ who studied the solubility and stability of the $\mathrm{PbO}-\mathrm{CO}_{2}-\mathrm{H}_{2} \mathrm{O}$ system; our results complete the photoinduced degradation pathway of minium.

\section{Experimental Section}

The $\mu \mathrm{XRF} / \mu \mathrm{XRPD}$ imaging experiments were performed at the microprobe station of the P06 Hard X-ray Micro/Nano-Probe beam line (PETRA III, DESY, Germany). A photon energy of $21 \mathrm{keV}$ was selected by means of a $\mathrm{Si}(111)$ double crystal monochromator. The beam was focused to $0.5 \times 0.5 \mu \mathrm{m}^{2}$ (hor. $\times$ vert.) employing a Kirkpatrick-Baez mirror optic. Fluorescence radiation was recorded by a Vortex-EM silicon drift detector placed perpendicular to the incident X-ray beam. Simultaneously diffraction signals were recorded in transmission geometry using a PILATUS $300 \mathrm{~K}$ area detector at a distance of approximately $15 \mathrm{~cm}$ behind the sample. Initial calibration of the diffraction setup was performed using a $\mathrm{LaB}_{6}$ reference sample. The software package PyMCA was used for spectral fitting of the fluorescence data, ${ }^{[23]}$ while whole pattern fitting of the diffraction data as well as the $\mu \mathrm{XRF}$ and $\mu \mathrm{XRPD}$ computed tomography reconstructions were performed using XRDUA.[5b] This software package provides several methods for obtaining crystalline-specific distributions from a large number of diffraction patterns typically obtained in $\mu$ XRPD imaging experiments. ${ }^{[7]}$ The virtual cross-section of the paint sample was reconstructed using the maximum-likelihood expectation-maximization (MLEM) algorithm. Additional details regarding the $\mu \mathrm{XRF} / \mu \mathrm{XRPD}$ tomography experiment as well as the computed X-ray absorption tomography measurement can be found in the Supporting Information.

Keywords: degradation $\cdot$ pigments $\cdot$ red lead $\bullet$ tomography $\cdot \mathrm{X}$ ray diffraction

[1] E. Dooryhée, M. Anne, I. Bardiès, J. L. Hodeau, P. Martinetto, S. Rondot J. Salomon, G. B. M. Vaughan, P. Walter, Appl. Phys. A 2005, 81, 663 667.

[2] a) P. Sciau, P. Goudeau, N. Tamura, E. Dooryhee, Appl. Phys. A 2006 83, 219-224; b) E. Welcomme, P. Walter, P. Bleuet, J. L. Hodeau, E. Dooryhee, P. Martinetto, M. Menu, Appl. Phys. A: Mater. Sci. Process. 2007, 89, 825-832.

[3] a) G. Van der Snickt, K. Janssens, J. Dik, W. De Nolf, F. Vanmeert, J. Jaroszewicz, M. Cotte, G. Falkenberg, L. Van der Loeff, Anal. Chem. 2012, 84, 10221-10228; b) F. Da Pieve, C. Hogan, D. Lamoen, J. Verbeeck, F. Vanmeert, M. Radepont, M. Cotte, K. Janssens, X. Gonze, G. Van Tendeloo, Phys. Rev. Lett. 2013, 111, 208302.

[4] W. De Nolf, J. Dik, G. Van der Snickt, A. Wallert, K. Janssens, J. Anal. At. Spectrom. 2011, 26, 910

[5] a) P. Bleuet, E. Welcomme, E. Dooryhee, J. Susini, J. L. Hodeau, P. Walter, Nat. Mater. 2008, 7, 468-472; b) W. De Nolf, K. Janssens, Surf. Interface Anal. 2010, 42, 411-418.

[6] M. Alvarez-Murga, P. Bleuet, J. L. Hodeau, J. Appl. Crystallogr. 2012, 45, 1109-1124.

[7] W. De Nolf, F. Vanmeert, K. Janssens, J. Appl. Crystallogr. 2014, 47, 1107-1117

[8] M. Geldof, L. Megens, J. Salvant, in Van Gogh's studio practice (Eds.: M. Vellekoop, M. Geldof, E. Hendriks, L. Jansen, A. de Tagle), Mercatorfonds, 2013, pp. 238-255.

[9] E. W. FitzHugh, in Artists' Pigments: A Handbook of their history and Characteristics, Vol. 1 (Ed.: R. L. Feller), Oxford University Press, 1985, pp. 109-139.

[10] N. Eastaugh, W. Valentine, T. Chaplin, R. Siddall, Pigment Compendium - A dictionary and optical microscopy of historical pigments, ButterworthHeinemann, 2008

[11] C. Higgitt, M. Spring, D. Saunders, National Gallery Technical Bulletin 2003, 24, 14.

[12] a) J. J. Boon, J. Van der Weerd, K. Keune, P. Noble, J. Wadum, in ICOM Committee for Conservation, 13th Triennial Meeting, Rio de Janeiro, Maney - Heritage, 2002, pp. 401-406; b) J. van der Weerd, J. J. Boon, M. Geldof, R. M. A. Heeren, P. Noble, Zeitschrift für Kunsttechnologie und Konservierung 2002, 16, 36-51.

[13] K. Keune, J. J. Boon, Stud. Conserv. 2007, 52, 161-176.

[14] S. Aze, J. M. Vallet, V. Detalle, O. Grauby, A. Baronnet, Phase Transitions 2008, 81, 145-154.

[15] D. Saunders, M. Spring, C. Higgitt, in 13th Triennial Meeting Rio De Janeiro Preprints, Vol. I, 2002, pp. 455-463.

[16] a) D. F. Haacke, P. A. Williams, J. Inorg. Nucl. Chem. 1981, 43, 406-406; b) P. Taylor, V. J. Lopata, Can. J. Chem. 1984, 62, 395-402.

[17] J. Tetreault, E. Cano, M. van Bommel, D. Scott, M. Dennis, M. G. Barthes-Labrousse, L. Minel, L. Robbiola, Stud. Conserv. 2003, 48, 237 250.

[18] G. Bertolotti, D. Bersani, P. P. Lottici, M. Alesiani, T. Malcherek, J. Schluter, Anal. Bioanal. Chem. 2012, 402, 1451-1457.

[19] a) D. Bersani, E. Campani, A Casoli, P. P. Lottici, I. G. Marino, Anal. Chim. Acta 2008, 610, 74-79; b) V. Matovic, N. Vaskovic, S. Eric, D. Sreckovic-Batocanin, Environ. Earth Sci. 2010, 60, 1153-1164.

[20] a) E. Kotulanová, P. Bezdička, D. Hradil, J. Hradilová, S. Švarcová, T Grygar, J. Cult. Herit. 2009, 10, 367-378; b) S. Aze, PhD thesis, Unversité de Droit, d'Economie et des Sciences d'Aix-Marseille 2005

[21] M. C. Corbeil, P. J. Sirois, Stud. Conserv. 2007, 52, 281-288.

[22] Y. G. Zhou, H. X. Lin, Q. Gu, J. L. Long, X. X. Wang, Rsc Advances 2012 , 2, 12624-12627.

[23] V. A. Sole, E. Papillon, M. Cotte, P. Walter, J. Susini, Spectrochim. Acta, Part B 2007, 62, 63-68. 
Entry for the Table of Contents (Please choose one layout)

Layout 1:

\section{COMMUNICATION}

Unravelling red lead degradation: The very rare lead carbonate mineral plumbonacrite was identified in a Van Gogh painting using combined microscopic X-ray fluorescence and $\mathrm{X}$-ray powder diffraction mapping and tomography methods. Thanks to the high spatial resolution and specificity of this technique an additional step in the photochemical degradation pathway of red lead is demonstrated.
Frederik Vanmeert, Dr. Geert Van der Snickt and Prof. Dr. Koen Janssens*

Page No. - Page No.

Plumbonacrite Identified by X-ray Powder Diffraction Tomography as a Missing Link during Degradation of Red Lead in a Van Gogh Painting 